\title{
Inmunología de la tiroides en la gestación y el posparto
}

\author{
Carla L. Macchia-de Sánchez ${ }^{1 *}$ y Javier A. Sánchez-Flórez ${ }^{2}$ \\ ${ }^{1}$ Programa de Medicina, Facultad de Ciencias de la Salud, Universidad del Magdalena; ${ }^{2}$ Clínica ESIMED. Santa Marta, Magdalena, Colombia
}

\section{Resumen}

Durante el embarazo ocurre una adaptación en la respuesta inmunitaria materna celular y humoral que incluye modificaciones tanto locales como sistémicas. Un órgano de especial importancia en esta regulación es la placenta. Estas modificaciones fisiológicas son capaces de afectar el curso y las manifestaciones clínicas de las enfermedades autoinmunes, entre ellas, las de la tiroides. Las tiroidopatías, a su vez, impactan en la gestación, incrementando el riesgo de complicaciones perinatales. El nacimiento provoca una caída de los productos hormonales placentarios y un cese del estrés gestacional. Se retorna al estado pregravídico con recuperación de la inmunidad celular. Por ello es ideal poder planificar el momento conveniente para lograr el embarazo, y cuando este ocurre, llevar un seguimiento adecuado que aumente las probabilidades de lograr una madre estable y un producto sano.

Palabras clave: Inmunidad celular. Inmunidad humoral. Glándula tiroides. Embarazo. Inmunidad maternoadquirida.

\section{Thyroid immunology in pregnancy and postpartum}

\section{Abstract}

During pregnancy, in the maternal cellular and humoral immune response occurs an adaptation which includes both local and systemic adaptations. An organ of special importance in this regulation is the placenta. These physiological modifications are capable of affecting the course and clinical manifestations of autoimmune diseases, including those of the thyroid. Thyroid diseases, in turn, influence pregnancy, increasing the risk of perinatal complications. Birth causes fall of placental hormone products and a cessation of gestational stress. The pregravidic state is returned with recovery of cellular immunity. It is therefore ideal to carry out a convenient pregnancy plan, with an adequate follow-up that increases the chances of achieving a stable mother and a healthy product.

Key words: Cellular immunity. Humoral immunity. Thyroid Gland. Pregnancy. Maternally acquired fetal immunity.

\section{Correspondencia:}

*Carla L. Macchia-de Sánchez

E-mail: cmacchia@unimagdalena.edu.co
Fecha de recepción: 14-09-2018

Fecha de aceptación: 12-11-2018

DOI: 10.24875/PER.M19000003
Disponible en internet: 25-03-2019 Perinatol Reprod Hum. 2019;33:14-22

www.perinatologia.mx 0187-5337/@ 2018. Instituto Nacional de Perinatología Isidro Espinosa de los Reyes. Publicado por Permanyer México SA de CV. Este es un artículo Open Access bajo la licencia CC BY-NC-ND (http://creativecommons.org/licenses/by-nc-nd/4.0/). 


\section{Introducción}

La unión exitosa entre individuos no emparentados de la misma especie asegura la diversidad biológica y disminuye la probabilidad de expresar enfermedades genéticas que se heredan con carácter recesivo. Para que esto sea posible es necesario que ocurra una adaptación del sistema inmunitario materno que prevenga el rechazo frente a la expresión de determinantes antigénicos diferentes en el producto. La tolerancia inmunológica se explica por una modificación en la respuesta materna celular y humoral, que incluye adaptaciones tanto locales como sistémicas. Esta adaptación ocurre desde etapas precoces de la gestación e involucra mecanismos de respuesta innata y adquirida. Un órgano de especial importancia en esta regulación es la placenta, la cual no solo representa una interfase maternofetal de intercambio gaseoso y de nutrientes, sino un verdadero y excepcional órgano transitorio neuroinmunoendocrinológico.

Sin embargo, los linfocitos B y T también pueden reaccionar contra antígenos propios, y si esta reactividad se sostiene en el tiempo, sobreviene una enfermedad autoinmune. De todas las enfermedades autoinmunes, las que afectan a la glándula tiroides son las más frecuentes, y son más prevalentes en la población femenina ${ }^{1}$. Se sabe que algunas células fetales, por ejemplo trofoblásticas y hematopoyéticas, alcanzan la circulación materna y pueden activar la respuesta inmunológica. Esta situación es conocida como microquimerismo y para algunos autores podría explicar, al menos en parte, la mayor prevalencia de estas enfermedades en la mujer ${ }^{2}$. Las células fetales pueden persistir en la circulación materna durante largo tiempo, de hecho, se han hallado quimeras en muestras de tejidos tiroideos de pacientes con tiroiditis de Hashimoto y enfermedad de Graves muchos años después de una gestación.

Por su parte, el curso de las enfermedades autoinmunes también se ve afectado por las modificaciones fisiológicas gestacionales, por ejemplo, la expansión de las células $T$ reguladoras conlleva una modulación de la respuesta inmunológica que se traduce en una caída en los niveles de autoanticuerpos maternos.

Teniendo esto en consideración, el pronóstico perinatal estará estrechamente relacionado con el grado de actividad de la enfermedad. Algunos autores señalan que el grado de actividad al momento de la concepción y durante los seis meses previos son factores predictivos de los resultados obstétricos y neonatales ${ }^{3}$.
La presencia de anticuerpos antitiroideos se ha relacionado con el desarrollo de complicaciones como el aborto y el parto pretérmino. A su vez, las pacientes eutiroideas con anticuerpos positivos pueden desarrollar hipotiroidismo debido al estrés de la gestación. En las pacientes hipotiroideas se ha observado mayor ocurrencia de malformaciones. En un estudio de casos y controles publicado en 2009, Browne, et al. reportaron una asociación estadísticamente significativa entre tiroideopatía materna con defectos cardíacos (OR: 1.5; IC 95\%: 1.0-2.3), hidrocefalia (OR: 2.9; IC 95\%: 1.6-5.2), hipospadias (OR: 1.6; IC 95\%: 1.0-2.5) y atresia anorrectal (OR: 2.4; IC 95\%: 1.2-4.6) ${ }^{4}$. Además, la carencia hormonal en etapas precoces de la gestación genera un impacto negativo en el neurodesarrollo embriofetal.

El presente trabajo tuvo como objetivo revisar algunos aspectos inmunológicos, histopatológicos y endocrinos relacionados con la fisiología tiroidea durante la gestación y el puerperio, tanto en mujeres sanas como en pacientes con enfermedades tiroideas autoinmunes, considerando asimismo su repercusión perinatal.

\section{Material y métodos}

Una vez seleccionadas las palabras clave de la lista de Descriptores en Ciencias de la Salud (DeCS) y del Medical Subject Headings (MeSH), en el idioma español e inglés, se realizó una búsqueda bibliográfica que incluyó libros de texto impresos y bases de datos electrónicas: Medline, Cochrane, Embase, Scopus y Web of Science, consultándose el material científico indexado y publicado entre 2008 y 2018. Se consideraron estudios de investigación básica, series de casos, artículos de revisión y metaanálisis. Para la selección del material publicado en revistas fueron considerados el lugar ocupado en el ranking Scimago Journal \& Country Rank (SJR), así como el factor de impacto al año de la publicación reflejado en la Web of Science-Journal Citation Reports (WoS-JCR). Para los libros fue excluyente la presencia de ISBN. Una vez analizada la bibliografía y evaluado el riesgo de sesgos, todos los autores seleccionaron las publicaciones que consideraron de mayor relevancia y rigor científico. Las discrepancias fueron resueltas mediante consenso general.

\section{Cambios inmunológicos durante la gestación}

Desde los inicios de la gestación se verifican en la madre una serie de adaptaciones locales y sistémicas que tienden a propiciar un microambiente óptimo para 
Tabla 1. Cambios inmunológicos durante el embarazo

\begin{tabular}{|c|c|}
\hline Predominio de respuesta inmunitaria & T helper 2 \\
\hline Microambiente placentario & $\begin{array}{l}\text { Células reguladoras (Treg) presentes en la placenta (también en la decidua y en } \\
\text { circulación materna) } \\
\text { Natural killer uterinas (uNK) } \\
\text { Macrófagos. Células dendríticas (presentadoras de antígeno) } \\
\text { Expresión de HLA-G en el trofoblasto (molécula de histocompatibilidad no clásica) } \\
\text { Expresión de FAS ligando } \\
\text { (Estos componentes promueven la aceptación y la protección del embarazo) }\end{array}$ \\
\hline Adaptación hormonal & $\begin{array}{l}\text { Primer trimestre y segundo trimestre temprano: ambiente proinflamatorio } \\
\text { Se posibilita la implantación del blastocisto, la invasión endometrial y el } \\
\text { reemplazo del músculo liso vascular en arteriolas maternas } \\
\text { Segundo trimestre: fase antiinflamatoria } \\
\text { Progesterona: reducción de la actividad de los linfocitos B } \\
\text { Estrógenos: caída en los niveles de autoanticuerpos } \\
\text { Tercer trimestre tardío: se reactivan los fenómenos inflamatorios que favorecen el } \\
\text { parto }\end{array}$ \\
\hline Evolución de algunas enfermedades autoinmunes & $\begin{array}{l}\text { Artritis reumatoidea } \rightarrow \text { mejora } \\
\text { Enfermedad de Graves } \rightarrow \text { mejora } \\
\text { Artritis psoriásica } \rightarrow \text { mejora } \\
\text { Lupus eritematoso sistémico } \rightarrow \text { empeora }\end{array}$ \\
\hline
\end{tabular}

el desarrollo adecuado del embarazo. Entre estas adaptaciones se hallan los cambios en el entorno hormonal, así como también en el sistema inmunitario, con la finalidad de prevenir el rechazo del producto.

Dentro de este contexto y en respuesta al aumento en la concentración estrogénica y al estímulo de citocinas, ocurre la expansión de un tipo celular especial: los linfocitos T CD4+ CD25+, denominados células reguladoras o Treg, que modulan la actividad inmunitaria celular y humoral (Th1 [T helper 1] y Th2 [T helper 2]). Estas células reguladoras se establecen tempranamente en la gestación, se acumulan principalmente en la decidua y se hallan también circulantes en sangre materna, con un pico en el segundo trimestre. La reactividad frente a los aloantígenos paternos es suprimida por las células Treg ${ }^{5,6}$.

Por su parte, los linfocitos Th1 están involucrados en la respuesta inmunitaria celular, y se cree que desempeñan un rol primordial en los procesos de implantación y placentación. La prevalencia de una respuesta inmunológica Th1 en las etapas precoces del embarazo, con liberación excesiva de citocinas proinflamatorias como el factor de necrosis tumoral (TNF) $\alpha$ y $\beta$, el interferón (IFN) $\gamma$, y las interleucinas (IL) 1, 2 y 6, puede ocasionar un fallo implantatorio y la subsecuente pérdida de la gestación. Entre tanto, los linfocitos Th2 median la respuesta inmunitaria humoral y liberan citocinas antiinflamatorias, como el factor de crecimiento de colonias de granulocitos y macrófagos (GM-CSF), y las IL-3, 4, 5, 10 y 13, las cuales previenen el rechazo inmunológico de los aloantígenos fetales ${ }^{3,7}$.

En el embarazo normal el sistema inmunitario materno inclina su balanza a un tipo de respuesta Th2. Esta es la razón por la cual ciertos trastornos autoinmunes mejoran durante la gestación. Por el contrario, en el puerperio se regresa al estado pregravídico con retorno de la respuesta celular habitual, pudiendo desencadenarse fenómenos como la tiroiditis posparto (Tabla 1).

Otra población celular presente en la placenta y en la decidua corresponde a las natural killer uterinas (uNK), de relevancia en los procesos de angiogénesis y placentación, como también en la defensa del producto frente a infecciones. Estas células promueven asimismo la tolerancia del embarazo ${ }^{8}$. Corresponden a una subpoblación de linfocitos que son CD56++/CD16-. Se cree que su función fundamental es la producción de diversas citocinas, como las IL-10 e IL-1, el TNF- $\alpha$, el factor de crecimiento transformante (TGF) $\beta$, el GM-CSF, el factor de crecimiento vascular endotelial (VEGF), etc. Las uNK también expresan inmunomoduladores como la glicodelina A, la galectina 1 y el TIM ( $T$ cell immunoglobulin and mucin domain) 3, lo que colabora con la inmunosupresión en la interfase placentaria ${ }^{9,10}$.

En la decidua se hallan además células presentadoras de antígeno: las células dendríticas, las cuales también participan en la tolerancia del producto. Modelos experimentales en ratones muestran que las altas concentraciones de gonadotropina coriónica y 
estradiol durante la gestación reducen la estimulación de los linfocitos $T$ por parte de estas ${ }^{11}$.

\section{Histopatología}

Es posible que factores tanto genéticos como ambientales estén implicados en el desarrollo de la autoinmunidad tiroidea. La exposición de antígenos como la peroxidasa, la tiroglobulina o el receptor de tirotropina (TSH) frente a células dendríticas (presentadoras de antígenos) activa la cascada de respuesta inmunológica que culmina con la infiltración linfocitaria glandular y la destrucción de las células foliculares ${ }^{12}$. Así lo demuestra el estudio histopatológico de la tiroides tanto en la tiroiditis de Hashimoto como en la enfermedad de Graves, donde se observan infiltrados inflamatorios crónicos de tipo linfoplasmocitarios.

\section{Tiroiditis de Hashimoto}

Corresponde a una tiroiditis linfocítica crónica. Macroscópicamente la glándula se encuentra aumentada de tamaño, con una superficie de corte blanda y pálida. En la observación microscópica se aprecian densos infiltrados linfoides con centros germinales y atrofia folicular. También se observan células de Hürthle (oncocíticas o de Askanazy). Los tipos celulares presentes en la tiroiditis de Hashimoto corresponden a linfocitos $B$ y linfocitos T CD4+ Th1, propios de una respuesta inmunitaria celular (Fig. 1).

\section{Enfermedad de Graves Basedow}

Macroscópicamente, la superficie de corte de la tiroides es firme y rojiza. Microscópicamente se encuentran infiltrados linfoides y se destaca la hiperplasia folicular con escaso coloide. Se hallan predominantemente linfocitos T CD4+ Th2, relacionados con un mecanismo de respuesta inmunitario humoral ${ }^{13,14}$.

\section{Tiroiditis posparto}

La tiroiditis posparto representa una tiroiditis linfocítica subaguda. En el estudio histopatológico glandular se observa un infiltrado linfocitario que alterna con centros germinales hiperplásicos, distribuidos entre los folículos ${ }^{15}$.

\section{Implicancias perinatales}

Como se ha señalado, productos placentarios como la progesterona, la hormona del crecimiento (GH) y los

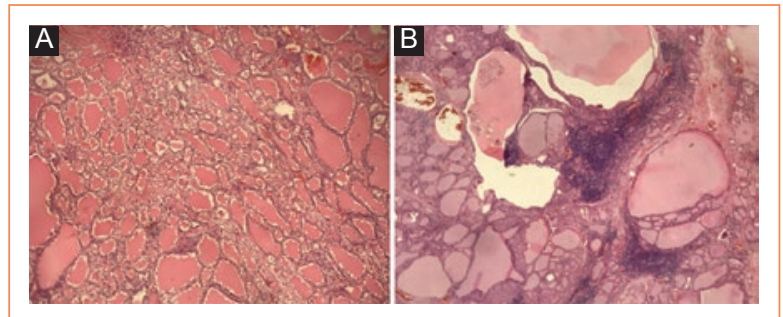

Figura 1. A: tiroides normal. Tinción hematoxilina-eosina, $10 \mathrm{X}$. Se observan folículos tiroideos tapizados por células de aspecto cúbico. B: tiroiditis de Hashimoto. Tinción hematoxilina-eosina, $10 \mathrm{X}$. Se aprecia el aumento del contenido coloide y la destrucción folicular; alternando, folículos linfoides (basófilos) (Imagen cortesía del Dr. José Abraham Jaramillo Osorio, CITOPAT).

estrógenos intervienen en la regulación del sistema inmunitario materno. La inmunomodulación del embarazo tiende a la supresión de la respuesta inmunitaria celular con una preservación de la respuesta humoral, lo que protege a la unidad fetoplacentaria del rechazo por histoincompatibilidad ${ }^{16,17}$. Estos fenómenos de adaptación afectan también el curso de las enfermedades tiroideas autoinmunes, tanto en el embarazo como en el puerperio.

\section{Anticuerpos antitiroideos}

La autoinmunidad tiroidea es más frecuente en la mujer, lo cual para ciertos autores tiene relación con el microquimerismo ${ }^{18}$. La prevalencia reportada es variable, alcanzando hasta un $20 \%$ en algunos estudios de tamizaje durante el primer trimestre. La positividad para anticuerpos antitiroideos aumenta el riesgo de desarrollar hipotiroidismo. A su vez, la autoinmunidad tiroidea en el primer trimestre se ha asociado a una mayor tasa de parto antes de la semana 32 (OR: 1.70; IC 95\%: 0.98-2.94) y de ruptura prematura de membranas (OR: 1.67; 95\% IC: 1.05-2.44) ${ }^{19}$.

Existen diferentes autoanticuerpos, dirigidos contra antígenos tiroideos específicos: anticuerpos antitiroglobulina (ATG), antiperoxidasa (ATPO) y anticuerpos antirreceptor de TSH (TRAb: receptor de hormona tiroestimulante). Si bien todos son capaces de atravesar la placenta, solo los últimos pueden afectar el funcionamiento de la tiroides fetal ${ }^{20}$.

\section{Anticuerpos antitiroglobulina}

Pueden observarse incluso en pacientes sin enfermedad tiroidea manifiesta. La prevalencia en mujeres en edad reproductiva es del $8.5-13.6 \%{ }^{21}$. 
Matalon, et al. demostraron que la inyección de tiroglobulina humana en ratones, con la consiguiente formación de anticuerpos, se asocia con un aumento en la reabsorción fetal ${ }^{22}$. Modelos experimentales en animales mostraron un aumento en la inmunogenicidad de la tiroglobulina ante el incremento en la administración de yodo. Se sugiere que el desenmascaramiento de un epítope oculto en dicha proteína explicaría el cambio en la respuesta autoinmunitaria ${ }^{23}$. En este sentido, un estudio de cohortes danés observó que luego de la aplicación del programa obligatorio de fortificación dietaria con yodo en el año 2000 , hubo un incremento de más del doble en la presencia de anticuerpos antitiroideos ${ }^{24}$.

\section{Anticuerpos antiperoxidasa}

Los ATPO, al igual que los ATG, pueden hallarse en pacientes sin tiroideopatía clínica. Son capaces de inducir citotoxicidad dependiente de anticuerpo, y suelen ser positivos en la tiroiditis de Hashimoto. Se ha observado una asociación entre la presencia de estos anticuerpos y diversos fallos reproductivos ${ }^{25}$. Un metaanálisis efectuado por Busnelli, et al. comparó los resultados perinatales en mujeres con y sin autoinmunidad tiroidea, encontrando en el primer grupo una menor tasa de nacidos vivos (OR: 0.65; IC 95\%: 0.49-0-87; $p=0.004)^{26}$. Han, et al. hallaron un riesgo 1.8 veces mayor de parto pretérmino en pacientes con ATPO en el primer y segundo trimestre de gestación ${ }^{27}$.

\section{Anticuerpos antirreceptor de tirotropina}

El receptor de TSH se expresa mayoritariamente en la superficie del tirocito, sin embargo, otros tipos celulares como hueso, tejido adiposo y fibroblastos también lo expresan. Los TRAb pertenecen a la clase de inmunoglobulinas (lg) G2, y se clasifican en estimulantes, neutros o bloqueantes, de acuerdo con el efecto que producen luego de unirse al receptor. La unión de los anticuerpos estimulantes al receptor provoca la liberación de hormonas tiroideas, lo que ocasiona hipertiroidismo materno, o incluso fetal, mediante el pasaje transplacentario de Ig. En este último caso, el hipertiroidismo se sospecha ante la detección ecográfica de bocio y la presencia de taquicardia fetal. Si bien la cordocentesis confirma el diagnóstico, su realización no está exenta de riesgos ${ }^{28}$. Afortunadamente, la frecuencia de hipertiroidismo fetal por esta causa es baja ( 1 en 4,000 a 1 en 40,000 embarazos) ${ }^{29}$.
Los anticuerpos bloqueantes, por su parte, pueden llevar a la atrofia glandular. No obstante los TRAb son característicos de la enfermedad de Graves, un pequeño porcentaje de paciente con tiroiditis de Hashimoto los presentan ${ }^{13}$.

\section{Tiroiditis de Hashimoto}

La prevalencia de hipotiroidismo oscila entre el 1 y el $2.5 \%$ de todos los embarazos, siendo la causa más frecuente la tiroiditis de Hashimoto. En esta entidad se detectan ATG y/o ATPO, implicados en los procesos de daño folicular tiroideo, debido al desarrollo de una respuesta inmunitaria celular. Numerosos estudios relacionan la presencia de estos anticuerpos con complicaciones perinatales como aborto recurrente, restricción del crecimiento, preeclampsia y parto pretérmino. Además, el inadecuado tratamiento del hipotiroidismo clínico materno, especialmente durante el primer trimestre, afecta al neurodesarrollo fetal.

El hipotiroidismo autoinmune tiende a permanecer más o menos estable durante el embarazo, con una disminución paulatina en los títulos de anticuerpos más notoria en el último trimestre. En algunas pacientes, especialmente aquellas con hipotiroidismos previos más leves, se precipitan fenómenos de destrucción glandular en el puerperio.

\section{Enfermedad de Graves Basedow}

El hipertiroidismo es menos frecuente durante el embarazo, con una prevalencia del $0.1-0.2 \%$. En más del $80 \%$ de los casos la causa es la enfermedad de Graves o bocio exoftálmico difuso. En esta entidad existen autoanticuerpos dirigidos contra el TRAb. Estos anticuerpos se unen al receptor activándolo, lo cual se traduce en un aumento en la secreción hormonal y bocio. Las pacientes con enfermedad de Graves también pueden presentar oftalmopatía, en un 30-60\% casos (ocasionada por infiltración inflamatoria de los músculos oculares y adipogénesis), y más raramente, dermopatía ${ }^{30}$.

Cuando la gestación inicia, incluso en pacientes bien controladas, la clínica de hipertiroidismo se puede exacerbar debido al efecto estimulante que ejerce la gonadotropina coriónica sobre los receptores de TSH. A medida que el embarazo transcurre, la expresión trofoblástica de inmunomoduladores de la respuesta $T$ helper tipo I y la aparición de células reguladoras se traducen en modificaciones clínicas y bioquímicas. Los 


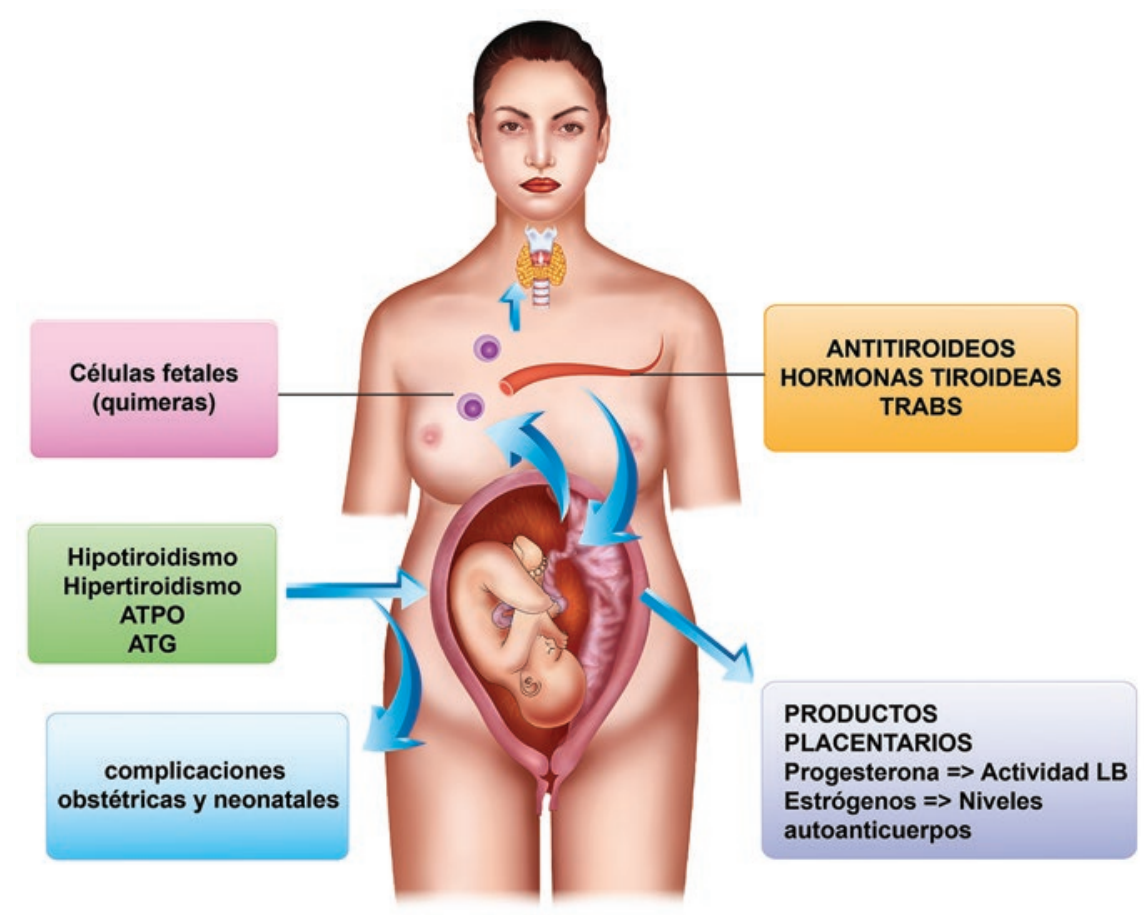

Figura 2. Patología tiroidea y gestación. La inmunoadaptación gestacional modifica la expresión clínica de las tiroidopatías autoinmunes. A su vez, la patología tiroidea aumenta el riesgo de complicaciones perinatales. Los antitiroideos, las hormonas tiroideas y los anticuerpos dirigidos contra el receptor de tirotropina son capaces de atravesar la placenta, impactando en la fisiología tiroidea fetal. Algunas células fetales pasan a la circulación materna (quimerismo), pudiendo activar fenómenos de autoinmunidad.

ATG: antitiroglobulina; ATPO: antiperoxidasa; TRAb: antirreceptor de tirotropina.

niveles de TRAb disminuyen, especialmente durante el tercer trimestre, lo que mejora las manifestaciones clínicas en este periodo, para volver a intensificarse cuando el embarazo finaliza ${ }^{31}$. Sin embargo, algunas pacientes con enfermedad de Graves no controlada pueden llegar a desarrollar insuficiencia cardíaca congestiva, y en el caso de sobrevenir tormenta tiroidea, requerir tratamiento en una Unidad de Cuidados Intensivos.

Dentro de las complicaciones perinatales deben mencionarse el aborto, la preeclampsia, el desprendimiento normoplacentario, la restricción del crecimiento intrauterino, el parto pretérmino y el óbito fetal, todas ellas mucho más frecuentes en la enfermedad no controlada ${ }^{32}$. A su vez, los anticuerpos TRAb, capaces de atravesar la placenta, pueden activar la tiroides fetal generando hipertiroidismo neonatal, con taquicardia, aceleración de la maduración ósea y malformaciones. Incluso en pacientes eutiroideas, con historia de tratamientos ablativos o quirúrgicos, la persistencia de anticuerpos circulantes puede impactar el curso de la gestación ${ }^{33}$ (Fig. 2).

\section{Autoinmunidad tiroidea y puerperio}

El nacimiento precipita la caída de los productos hormonales placentarios y ocasiona un cese del estrés gestacional. Se retorna al estado pregravídico con recuperación nuevamente de la inmunidad celular, lo que desencadena en ciertas pacientes un fenómeno de tiroiditis con destrucción folicular (tiroiditis posparto). La presencia de autoinmunidad positiva durante las etapas precoces de la gestación, especialmente anticuerpos ATPO, incrementa el riesgo de tiroiditis posparto y depresión puerperal. Con relación a la enfermedad de Graves, el periodo puerperal se constituye en un factor de riesgo tanto para su inicio, si no estaba presente, como para su exacerbación.

\section{Tiroiditis posparto}

Es la ocurrencia de disfunción tiroidea (no enfermedad de Graves) en mujeres previamente eutiroideas, la cual se desarrolla en los doce meses siguientes al 
término de una gestación, aunque hay casos reportados de tiroiditis luego de un aborto ${ }^{34}$. Su prevalencia es de aproximadamente el $5 \%{ }^{20}$. Ocurre más frecuentemente en mujeres con títulos elevados de ATPO, con diabetes tipo I y en pacientes con hepatitis crónica viral ${ }^{35}$.

Es una afectación no dolorosa de la glándula tiroides que clásicamente evoluciona en tres etapas. La primera de ellas consiste en un periodo de entre dos a tres meses de tirotoxicosis inicial. En esta etapa hay una liberación masiva de hormonas a la circulación debido a un daño en los tirocitos mediado por la inmunidad celular. Cuando pasa esta etapa sobreviene una fase de hipotiroidismo que ocurre por agotamiento glandular, y que se prolonga durante tres meses aproximadamente. Finalmente, se retorna al estado eutiroideo. Los hallazgos de laboratorio muestran fluctuación en los niveles de TSH y hormonas tiroideas en relación al periodo de la tiroiditis que está atravesando. El tratamiento suele reservarse para la etapa de hipotiroidismo.

Debe señalarse que no todas las pacientes evidencian este patrón evolutivo, y que muchas de ellas presentan una recuperación transitoria con recaída en algunos años. Stagnaro Green, et al. publicaron en 2011 sus hallazgos sobre una cohorte de 4,384 pacientes del sur de Italia. El 3.9\% $(n=169)$ desarrolló tiroiditis posparto, persistiendo el hipotiroidismo al año en el $54 \%$ de los casos. La tiroiditis fue más frecuente en las pacientes con factores de riesgo (antecedentes personales o familiares de tiroideopatía autoinmune, bocio, irradiación cervical o historia de aborto o parto pretérmino) y en las pacientes con ATPO positivos ${ }^{36}$.

\section{Depresión puerperal}

Wesseloo, et al. publicaron un estudio de cohorte sobre 1,075 gestantes, en las cuales de determinó la positividad para ATPO al inicio del embarazo. El seguimiento durante un año posterior al nacimiento mostró un incremento del riesgo de depresión a los cuatro meses posparto (OR: 3.8; IC 95\%: 1.3-11.6) en el grupo con autoinmunidad positiva ${ }^{37}$. A su vez, una revisión sistemática efectuada por Dama, et al. sugiere que la positividad para ATPO en la primera mitad de la gestación se asocia a depresión concurrente e igualmente podría constituirse en un predictor de depresión puerperal ${ }^{38}$. Estos hallazgos se han observado también en modelos experimentales en ratones, correlacionando los títulos de autoanticuerpos con el grado de alteración en la conducta del animal ${ }^{39}$.

\section{Impacto neonatal de la autoinmunidad tiroidea}

Los anticuerpos estimulantes dirigidos contra el receptor de TSH, presentes en la enfermedad de Graves, son capaces de atravesar la placenta desde la segunda mitad de la gestación, pudiendo ocasionar hipertiroidismo fetal. La presencia de taquicardia persistente (frecuencia cardíaca fetal $\geq 160$ latidos por minuto) 0 el descubrimiento de un bocio fetal hacen sospechar esta condición. También puede observarse polihidramnios debido a la obstrucción esofágica y traqueal secundaria al bocio ${ }^{40}$.

Sin embargo, como los antitiroideos atraviesan la placenta, el hallazgo de bocio fetal podría igualmente sugerir hipotiroidismo en el producto. En este caso una cordocentesis podría estar indicada. Se recomienda efectuarla solo en casos de no arribar a un diagnóstico concluyente con base en la valoración clínica y ecográfica ${ }^{41}$. El feto también puede desarrollar hipotiroidismo ante la presencia de anticuerpos maternos bloqueantes del receptor de TSH, situación que es menos frecuente. Debe destacarse que el riesgo de pasaje transplacentario de anticuerpos subsiste incluso en gestantes eutiroideas con antecedentes de enfermedad de Graves, tratadas previamente con cirugía o yodo radiactivo, debido a la persistencia de Ig en la circulación materna.

Son factores de riesgo asociados al desarrollo de un hipertiroidismo fetal y neonatal: el inadecuado control de la enfermedad materna, los altos títulos de anticuerpos estimulantes y la historia de hipertiroidismo neonatal en gestaciones previas ${ }^{42}$.

La Asociación Americana de Tiroides recomienda determinar los niveles de TRAb entre las semanas 20 y 24 de gestación en las pacientes con enfermedad de Graves actual, y en aquellas con enfermedad pasada tratadas con tiroidectomía o radio yodo. El riesgo para la ocurrencia de hipertiroidismo fetal es alto si los niveles de lg se encuentran dos a tres veces por encima del límite superior del rango normal de referencia ${ }^{20}$.

Aproximadamente el 1-5\% de los recién nacidos hijos de madres con enfermedad de Graves desarrollan hipertiroidismo neonatal. La presentación más frecuente consiste en un cuadro de tirotoxicosis transitoria, que se inicia poco después del nacimiento y que se mantiene durante semanas o meses hasta que los anticuerpos maternos desaparecen de circulación. Estos niños pueden evidenciar también defectos del desarrollo, como craneosinostosis y microcefalia. En ocasiones la clínica es más pronunciada, presentando el recién 
nacido fiebre, hiperexcitabilidad, distrés respiratorio e inestabilidad hemodinámica. Algunos casos más severos desembocan en insuficiencia cardíaca y muerte.

En un estudio multicéntrico retrospectivo, efectuado en 10 centros obstétricos en hospitales de asistencia pública en París, se estudiaron los registros de 415 mujeres con enfermedad de Graves. Se diagnosticó hipertiroidismo neonatal en 23 recién nacidos (5.5\%). Veinte de estos niños eran hijos de madres que recibían antitiroideos en el tercer trimestre de gestación. Se halló asociación con un nacimiento más temprano y menor peso al nacer. Considerando la totalidad de neonatos, hubo un $19.8 \%$ de admisión en cuidados intensivos, el $6.9 \%$ de los pacientes presentaron niveles elevados de tiroxina (T4) libre y un 20\% evidenció TSH por debajo del percentil $2.5^{43}$.

\section{Conclusiones}

Las enfermedades autoinmunes, especialmente las de la tiroides, son frecuentes en mujeres en edad reproductiva. Las modificaciones fisiológicas propias del embarazo, relacionadas con los mecanismos de inmunomodulación, influencian su curso y manifestaciones clínicas. Paralelamente, las enfermedades autoinmunes también influyen en la gestación, entrañando un riesgo mayor de complicaciones perinatales. Por esta razón es ideal poder planificar el momento conveniente para lograr el embarazo, y cuando este ocurre, llevar un seguimiento adecuado que aumente las probabilidades de lograr un producto sano y una madre en las condiciones óptimas posibles. Finalizada la gestación, debe asegurarse el seguimiento especialmente en el primer año posparto, teniendo en cuenta que muchas pacientes con autoinmunidad tiroidea (ATG y ATPO) experimentan recaídas luego de un lapso variable, derivando en hipotiroidismo permanente.

\section{Agradecimientos}

Los autores agradecen al Dr. José Abraham JaramiIlo Osorio (Laboratorio CITOPAT) por las imágenes histológicas compartidas.

\section{Conflicto de intereses}

Los autores declaran que no existe conflicto de intereses.

\section{Financiación}

La presente revisión se ha realizado con el apoyo del Proyecto Capital Semilla, financiado por la Universidad de Magdalena (Colombia).

\section{Responsabilidades éticas}

Protección de personas y animales. Los autores declaran que para esta investigación no se han realizado experimentos en seres humanos ni en animales.

Confidencialidad de los datos. Los autores declaran que han seguido los protocolos de su centro de trabajo sobre la publicación de datos de pacientes.

\section{Derecho a la privacidad y consentimiento infor-} mado. Los autores declaran que en este artículo no aparecen datos de pacientes.

\section{Bibliografía}

1. McLeod DS, Cooper DS. The incidence and prevalence of thyroid autoimmunity. Endocrine. 2012;42:252-65.

2. Weetman AP. Immunity, thyroid function and pregnancy: molecular mechanisms. Nat Rev Endocrinol. 2010;(6):311-18.

3. Carvalheiras G, Faria R, Braga J, Vasconcelos C. Fetal outcome in autoimmune diseases. Autoimmun Rev. 2012;11:520-30.

4. Browne ML, Rasmussen SA, Hoyt AT, Waller DK, Druschel CM, Caton AR, et al. Maternal thyroid disease, thyroid medication use, and selected birth defects in the National Birth Defects Prevention Study. Birth Defects Res A Clin Mol Teratol. 2009;85:621-8.

5. Iyidir OT, Degertekin CK, Sonmez C, Yucel AA, Erdem M, Akturk M, et al. The effect of thyroid autoimmunity on T-cell responses in early pregnancy. J Reprod Immunol. 2015;110:61-6.

6. Gaberšček S, Zaletel K. Thyroid physiology and autoimmunity in pregnancy and after delivery. Expert Rev Clin Immunol. 2011;7(5):697-706.

7. Raghupathy R, Kalinka J. Cytokine imbalance in pregnancy complications and its modulation. Front Biosci 2008;13:985-94.

8. Arias ME, Villegas J. Avances en inmunidad gestacional. Int J Morphol. 2010;28(3):713-18.

9. Faas MM, de Vos P. Uterine NK cells and macrophages in pregnancy. Placenta. 2017;56:44-52.

10. Shrestha S, Sharma P, Kumar P, Saxena SP, Sharma R. Natural killer cells: An insight into its role in pregnancy. J Clin Diagn Res. 2018;12(1): BE01-7.

11. Segerer SE, Müller N, van den Brandt J, Kapp M, Dietl J, Reichardt HM, et al. Impact of female sex hormones on the maturation and function of human dendritic cells. Am J Reprod Immunol. 2009;62:165-73.

12. De Leo S, Pearce EN. Autoimmune thyroid disease during pregnancy. Lancet Diabetes Endocrinol. 2018;6(7):575-86.

13. Michalek K, Morshed SA, Latif R, Davies TF. TSH receptor autoantibodies. Autoimmun Rev. 2009;9:113-6.

14. Carton J. Manual de patología clínica. 1. a ed. McGraw-Hill Interamericana de España; 2013.

15. Argueta Sandoval VL. Patología de la tiroides. En: Valencia Mayoral PF, Rodríguez JA. Patología. McGraw-Hill Interamericana de España; 2014.

16. Klecha AJ, Barreiro Arcos ML, Frick L, Genaro AM, Cremaschi G. Immune-endocrine interactions in autoimmune thyroid diseases. Neuroimmunomodulation. 2008;15:68-75.

17. Sammaritano LR. Pregnancy in rheumatic disease patients. J Clin Rheumatol. 2013;19(5):259-66.

18. Friedrich N, Schwarz S, Thonack J, John U, Wallaschofski H, Völzke H. Association between parity and autoimmune thyroiditis in a general female population. Autoimmunity. 2008;41(2):174-80.

19. Haddow JE, Cleary-Goldman J, McClain MR, Palomaki GE, Neveux LM, Lambert-Messerlian G, et al. Thyroid peroxidase and thyroglobulin antibodies in early pregnancy and preterm delivery. Obstet Gynecol. 2010;116(1):58-62.

20. Alexander EK, Pearce EN, Brent GA, Brown RS, Chen H, Dosiou C, et al. Guidelines of the American Thyroid Association for the Diagnosis and 
Management of Thyroid Disease During Pregnancy and the Postpartum. Thyroid. 2017;27(3):315-89.

21. Kitzmiller JL, Jovanovich L, Brown F, Coustan D, Reader DM, editores Managing preexisting diabetes and pregnancy. Technical reviews and consensus recommendations for care. $1^{\text {st }}$ ed. Alexandria, Virginia: American Diabetes Association; 2008

22. Matalon ST, Blank M, Levy Y, Carp HJ, Arad A, Burek L, et al. The pathogenic role of anti-thyroglobulin antibody on pregnancy: evidence from an active immunization model in mice. Hum Reprod. 2003;18(5): 1094-9.

23. Fiore $E$, Latrofa $F$, Vitti $P$. lodine, thyroid autoimmunity and cancer. Eur Thyroid J. 2015;(4)1:26-35.

24. Bliddal S, Boas M, Hilsted L, Friis-Hansen L, Juul A, Larsen T, et al. Increase in thyroglobulin antibody and thyroid peroxidase antibody levels, but not preterm birth-rate, in pregnant Danish women upon iodine fortification. Eur J Endocrinol. 2017;176(5):603-12.

25. Fumarola A, Grani G, Romanzi D, Del Sordo M, Bianchini M, Aragona $A$, et al. Thyroid function in infertile patients undergoing assisted reproduction. Am J Reprod Immunol. 2013;70(4):336-41.

26. Busnelli A, Paffoni A, Fedele L, Somigliana E. The impact of thyroid autoimmunity on IVF/ICSI outcome: a systematic review and meta-analysis. Hum Reprod Update. 2016;22(6):775-90.

27. Han Y, Mao LJ, Ge X, Huang K, Yan SQ, Ren LL, et al. Impact of maternal thyroid autoantibodies positivity on the risk of early term birth: Ma'anshan Birth Cohort Study. Endocrine. 2018;60(2):329-38.

28. Kennedy RL, Malabu UH, Jarrod G, Nigam P, Kannan K, Rane A. Thyroid function and pregnancy: Before, during and beyond. J Obstet Gynaecol. 2010;30(8):774-83.

29. Tingi $E$, Syed AA, Kyriacou A, Mastorakos G, Kyriacou A. Benign thyroid disease in pregnancy: A state of the art review. J Clin Transl Endocrinol. 2016;6:37-49.

30. Wiesweg B, Johnson KTM, Eckstein AK, Berchner-Pfannschmidt U. Current insights into animal models of graves' disease and orbitopathy. Horm Metab Res. 2013;45(8):549-55.

31. Bucci I, Giuliani C, Napolitano G. Thyroid-stimulating hormone receptor antibodies in pregnancy: Clinical relevance. Front Endocrinol. 2017;8:137.

32. Aggarawal N, Suri V, Singla R, Chopra S, Sikka P, Shah VN, et al Pregnancy outcome in hyperthyroidism: a case control study. Gynecol Obstet Invest. 2014;77(2):94-9.
33. Donnelly MA, Wood C, Casey B, Hobbins J, Barbour LA. Early severe fetal Graves disease in a mother after thyroid ablation and thyroidectomy. Obstet Gynecol. 2015;125(5):1059-62.

34. Samuels MH. Subacute, silent, and postpartum thyroiditis. Med Clin North Am. 2012;96(2):223-33.

35. De Groot L, Abalovich M, Alexander EK, Amino N, Barbour L, Cobin RH, et al. Management of thyroid dysfunction during pregnancy and postpartum: An Endocrine Society Clinical Practice Guideline. J Clin Endocrinol Metab. 2012;97(8):2543-65.

36. Stagnaro-Green A, Schwartz A, Gismondi R, Tinelli A, Mangieri T, Negro R. High rate of persistent hypothyroidism in a large-scale prospective study of postpartum thyroiditis in Southern Italy. J Clin Endocrinol Metab. 2011;96(3):652-7.

37. Wesseloo R, Kamperman AM, Bergink V, Pop VJM. Thyroid peroxidase antibodies during early gestation and the subsequent risk of first-onset postpartum depression: A prospective cohort study. J Affect Disord. 2018;225:399-403

38. Dama M, Steiner M, van Lieshout R. Thyroid peroxidase autoantibodies and perinatal depression risk: A systematic review. J Affect Disord. 2016;198:108-21.

39. Iseme RA, McEvoy M, Kelly B, Agnew L, Attia J, Walker FR. Autoantibodies and depression. Evidence for a causal link? Neurosci Biobehav Rev. 2014;40:62-79.

40. Samuels SL, Namoc SM, Bauer AJ. Neonatal thyrotoxicosis. Clin Perinatol. 2018;45(1):31-40.

41. Garber JR, Cobin RH, Gharib H, Hennessey JV, Klein I, Mechanick JI, et al. Clinical practice guidelines for hypothyroidism in adults: cosponsored by the American Association of Clinical Endocrinologists and the American Thyroid Association. Endocr Pract. 2012;18(6):988-1028.

42. Lazarus $\mathrm{J}$. Thyroid regulation and dysfunction in the pregnant patient. En: De Groot LJ, Chrousos G, Dungan K, Feingold KR, Grossman A, Hershman JM, et al., editores. Endotext [Internet]. South Dartmouth (MA): MDText.com; 2000. Disponible en: https://www.ncbi.nlm.nih.gov/ books/NBK279059.

43. Banigé $M$, Polak M, Luton D. Prediction of neonatal hyperthyroidism. J Pediatr. 2018;197:249-54.e1.

44. Mor G, Cárdenas I. The immune system in pregnancy: a unique complexity. Am J Reprod Immunol. 2010;63:425-33. 